\title{
Invasive Breast Carcinoma Arising in a Nipple Adenoma After 15 Years: Report of a Rare Case and Literature Review
}

\author{
Muhammad Abdulwaasey ${ }^{1}$, Muhammad Usman Tariq ${ }^{1}$, Khurram Minhas $^{2}$, Naila Kayani ${ }^{3,4}$ \\ 1. Histopathology, Pathology and Laboratory Medicine, Aga Khan University Hospital, Karachi, PAK 2. Histopathology, \\ Aga Khan University Hospital, Karachi, PAK 3. Pathology and Laboratory Medicine/Histopathology, Aga Khan \\ University Hospital, Karachi, PAK 4. Pathology and Microbiology, Aga Khan University Hospital, Karachi, PAK
}

Corresponding author: Muhammad Usman Tariq, muhammadusmantariq84@gmail.com

\begin{abstract}
Nipple adenoma (NA) is a rare benign breast neoplasm that seldom co-exists with breast carcinoma (BC). Majority of these $\mathrm{BC}$ are separate from NA, and their origin from NA is an extremely rare event. We herein describe a case of 65 -year-old female who had a painless lump for 15 years which increased in size and ulcerated for last six months. Microscopic examination of the wedge biopsy of nipple showed features of NA at superficial aspect and invasive carcinoma from it at the deeper aspect. The patient underwent mastectomy and axillary clearance, which revealed a 4-cm invasive breast carcinoma, no special type with axillary lymph node involvement. The patient received adjuvant chemotherapy, radiotherapy and adjuvant hormonal therapy. The patient is alive and disease-free after 36 months.
\end{abstract}

NA should be carefully evaluated for co-existent BC because it completely changes the treatment plan and prognosis.

Categories: Pathology, Oncology

Keywords: nipple adenoma, breast cancer, paget's disease, nipple discharge

\section{Introduction}

Nipple adenoma (NA) is an uncommon benign breast neoplasm, involving lactiferous ducts orifices, surrounding stroma and overlying epidermis of nipple [1,2]. It most commonly occurs in fifth decade of life and affects both genders [1]. It presents as a palpable mass with nipple distortion and skin changes, such as erythema, thickening, erosion, ulceration and nipple discharge [3-5]. Ultrasound is the most clinically useful imaging modality on which NA appears as a well-defined hypoechoic mass. Mammogram and magnetic resonance imaging are also used for radiological assessment $[2,6]$. Histologically, tumor shows proliferation of benign ductal and glandular structures, involving the nipple and lactiferous ducts. Variable combinations of sclerosing adenosis, papillomatosis and hyperplastic changes are observed [1,7,8]. Complete surgical resection is the only treatment option [2]. Recurrence is observed in incompletely excised tumors [2].

Received 05/08/2020

Review began 06/03/2020 Review ended 06/05/2020 Published 06/12/2020

\section{() Copyright 2020}

Abdulwaasey et al. This is an open access article distributed under the terms of the Creative Commons Attribution License CC-BY 4.0., which permits unrestricted use, distribution, and reproduction in any medium, provided the original author and source are credited.
A small proportion of NA also presents with co-existent ductal carcinoma in situ (DCIS) and/or invasive carcinoma, which alters the treatment and prognosis of these tumors [4,5,7-11]. We herein describe the clinicopathological features of an invasive carcinoma arising from NA. We also reviewed the literature for NA cases with co-existent carcinoma.

\section{Case Presentation}

A 65 -year-old female presented with a history of painless right subareolar mass for 15 years. The mass became painful for last three years and it gradually increased in size with nipple ulceration for last six months. On physical examination, the nipple was ulcerated with surrounding erythema. A firm subareolar mass and axillary lymph nodes were palpable. Ultrasonogram showed a hypoechoic lesion in subareolar/retroareolar region measuring 3.5 x 3 x $2.4 \mathrm{~cm}$. Mammogram also revealed a spiculated mass. Clinical diagnosis was Paget's disease and associated malignancy. Wedge biopsy was performed. Microscopically, superficial aspect showed multiple distended lactiferous ducts filled with proliferating epithelial cells showing papillomatosis and hyperplastic changes. These cells showed mild atypia and occasional mitoses. Deeper aspect showed haphazard nests, trabeculae and tubules of neoplastic cells against fibrous background stroma (Figure 1). 


\section{Cureus}

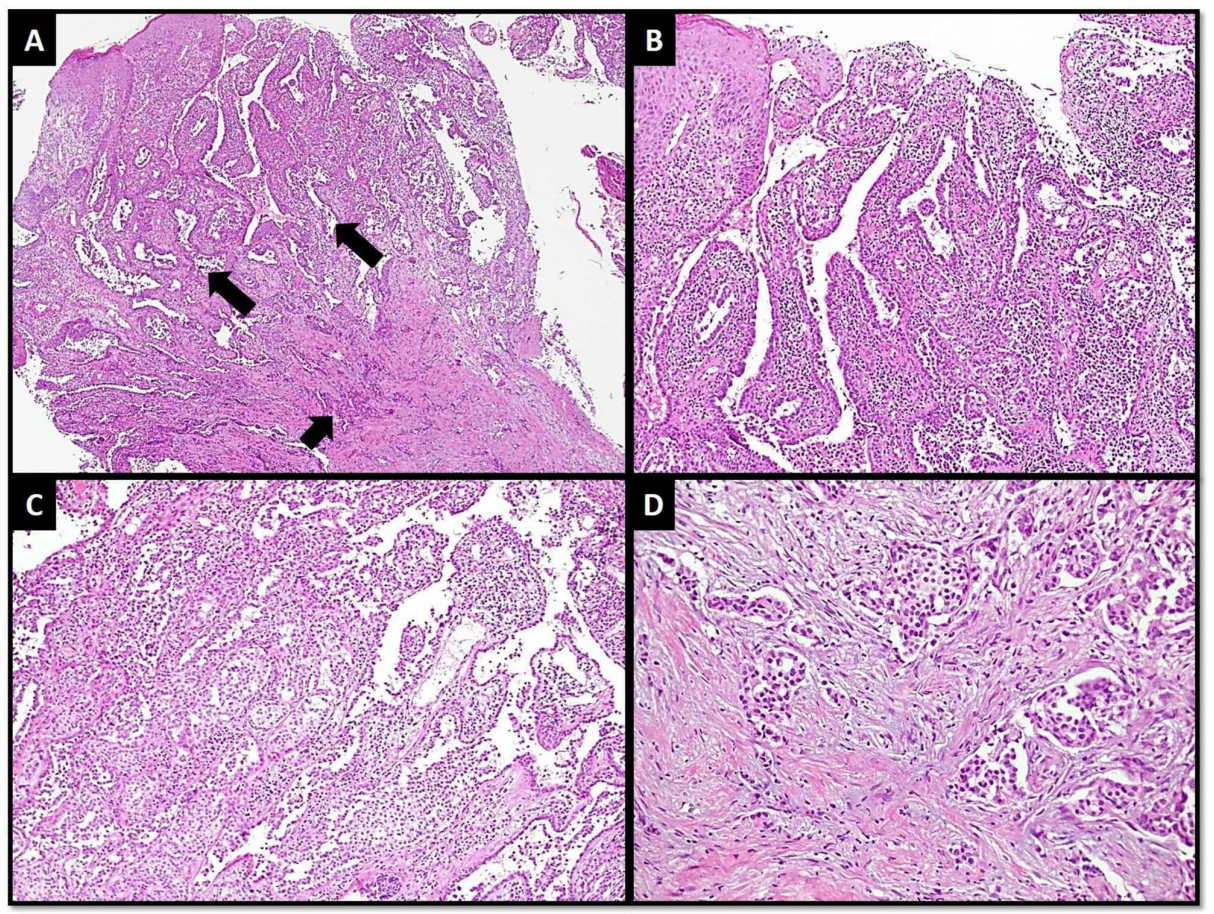

FIGURE 1: (A) Low-power view of tumor showing features of nipple superficially (larger arrows) and invasive carcinoma at deeper aspect (shorter arrow). (B) Papillomatous pattern in NA. (C) Hyperplastic changes in NA. (D) Nest and tubules of invasive carcinoma.

NA, Nipple adenoma

Paget's cells were also appreciated in the overlying dermis. An intact myoepithelial cell layer was present around these ducts at the superficial aspect while it was absent around nests and tubules at the deeper aspect (Figure 2).

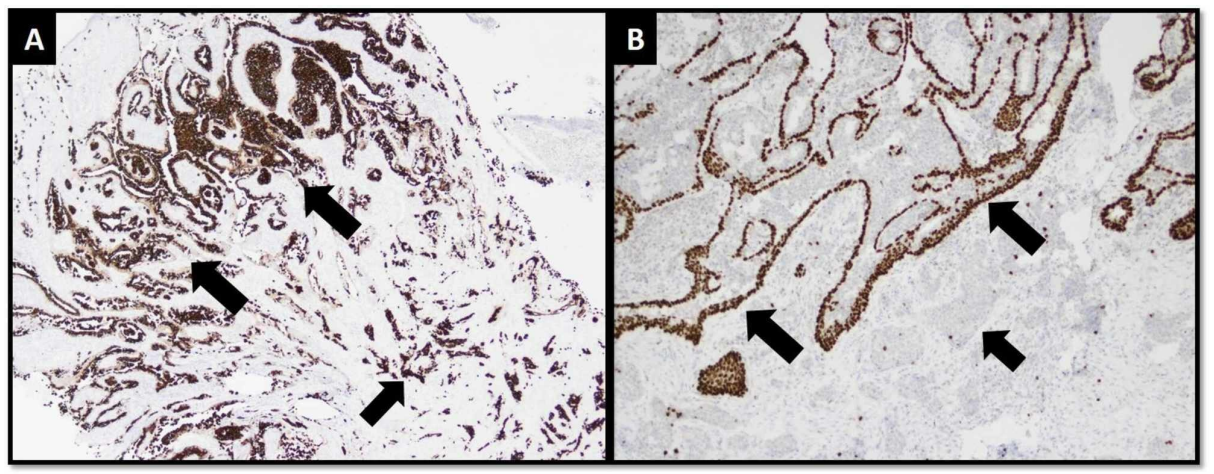

FIGURE 2: IHC stains. (A) Cytokeratin CAM5.2 highlights papillomatous and hyperplastic nature of NA superficially (larger arrows) and infiltrative pattern of carcinoma at deeper aspect (short arrow). (B) p63 highlights intact myoepithelial cell layer around ducts of NA (larger arrows) and loss of myoepithelial cell layer around invasive carcinoma (short arrow).

IHC, immunohistochemistry; NA, nipple adenoma.

The diagnosis of "invasive breast carcinoma, no special type (NST) arising in the background of nipple adenoma” was made. 
The patient underwent subsequent mastectomy and axillary clearance. Grossly, a gray white firm infiltrating lesion measuring $4 \times 3.5 \times 2.2 \mathrm{~cm}$ was identified beneath nipple and areola. The rest of the breast was unremarkable. Microscopic examination revealed "invasive breast carcinoma, no special type (NST) grade II”. Focal residual NA and Paget's disease were also appreciated. Two out of 18 lymph nodes were involved by metastatic carcinoma.

The patient received adjuvant chemotherapy, radiotherapy and hormonal therapy. The patient is alive and disease-free after 36 months of follow-up.

\section{Discussion}

NA has been reported in $1.2 \%$ cases of breast carcinoma (BC), who underwent mastectomy [7]. Another large review of 224 NA cases reported co-existent BC in 37 (16.5\%) cases. In 19 of these cases, carcinoma was ipsilateral, coincidental and separate from NA [7]. Involvement of contralateral breast by invasive carcinoma has also been rarely reported [4]. The invasive carcinoma is of ductal type in vast majority and lobular type has occasionally been reported [7,10]. Over a period of last 35 years, 75 cases of NA had been diagnosed at our institution [12]. Three (4\%) cases had co-existent invasive carcinoma (of ductal type). Besides the case described in this report, one of the patients had ipsilateral invasive carcinoma and extensive DCIS which was separate from NA. The other patient had contralateral invasive carcinoma and extensive DCIS.

Koerner comprehensively summarized the findings of 15 cases which were reported in different studies as "in situ or invasive carcinoma arising directly from florid papillomatosis/nipple adenoma" [7]. Eight patients had invasive ductal carcinoma (IDC), two had IDC and DCIS, and two had DCIS only [7]. In one of the cases, synchronous IDC in other quadrant of ipsilateral breast was identified. In another case of DCIS arising in NA, DCIS was also appreciated in contralateral breast [7]. In three cases, Koerner did not find sufficient evidence of NA [7]. In males, almost half of the NAs are associated with carcinoma and this can be attributed to the subareolar origin of majority of BC in males. The origin of BC from NA raises the possibility of precancerous nature of NA [7]. Clinical presentation and disease course in our case also favors this possibility since the lesion (NA) remained asymptomatic for years, as long as it was benign. The changes developed recently, most likely with malignant transformation.

A recent study reported PIK3CA activating mutations in more than 50\% cases of NA. Although these mutations are observed in approximately $30 \%$ BC, this does not imply a causal relationship since these mutations are more frequently observed in other benign proliferative breast lesions [13].

Four reports of in situ and invasive carcinoma co-existing with NA were further published in the literature [8-11]. Lee et al. reported a case exhibiting three foci of multicentric BC, all separate from NA. One of these tumors was invasive lobular carcinoma, second showed mixed features of ductal and lobular carcinoma while the morphology of the smallest lesion was not described [10]. Sasi et al. reported bilateral NAs. DCIS with microinvasion was appreciated unilaterally [9]. In a series of 13 NA cases, Di Bonito et al. identified DCIS in only a single case [8]. Zhao et al. reported a case of NA co-existing and intraductal papillary carcinoma [11].

Histological diagnosis of carcinoma arising in NA can be challenging because of complex architectural patterns observed in NA, such as comedonecrosis, cribriform and micropapillary patterns. Focal necrosis, cytologic atypia and mitotic figures are not common. Sclerosing papillomatous pattern can resemble pseudo-invasion and the picture gets complicated further with focal loss of myoepithelial markers $[7,8]$. Immunohistochemical (IHC) markers are helpful in highlighting myoepithelial cell layer around majority of the ducts and tubules of NA [7-9]. Careful sampling and examination of the deeper aspect of the lesion should be done to rule out the presence of invasive carcinoma. A panel of IHC markers should be applied to assess the presence/absence of myoepithelial cell layer. It should also be kept in mind that the invasive carcinoma can arise from larger lactiferous ducts (not harboring NA) [7,14].

Paget's disease in the overlying dermis is commonly observed and it is considered a reliable indicator of malignancy arising in NA. IHC markers cytokeratin CAM5.2 and CK7 are helpful in highlighting Paget's cells [7]. In cases without concomitant Paget's disease and invasive carcinoma, diagnosis of "DCIS arising in NA" should be made with great caution [7].

After complete removal of NA, the risk of subsequent carcinoma development is low [4]. However, in situ and invasive carcinoma have been reported to occur in three patients, 3-17 years after complete excision of NA [7]. Therefore, clinical follow-up is a wise approach [4].

\section{Conclusions}

We conclude that co-existence of NA with BC is an extremely rare event of prime importance. It should always be kept in mind and carefully searched for during histological evaluation of nipple biopsy specimens.

\section{Additional Information}




\section{Disclosures}

Human subjects: Consent was obtained by all participants in this study. Ethics Review Committee, Aga Khan University Hospital issued approval NA. This is a retrospective review of clinicopathological findings which were collected from patient's records and reviewing the microscopic glass slides. Therefore, approval from institution's Ethics Review Committee was not sought. . Conflicts of interest: In compliance with the ICMJE uniform disclosure form, all authors declare the following: Payment/services info: All authors have declared that no financial support was received from any organization for the submitted work. Financial relationships: All authors have declared that they have no financial relationships at present or within the previous three years with any organizations that might have an interest in the submitted work. Other relationships: All authors have declared that there are no other relationships or activities that could appear to have influenced the submitted work.

\section{References}

1. Lester SC, Lee AHS: Nipple adenoma. Breast Tumours. WHO Classificaton of Tumours Series, 5th Edition. WHO Classification of Tumours Editorial Board (ed): International Agency for Research on Cancer Press, Lyon, France; 2019. 2:182-183.

2. Tatterton MR, Fiddes R: Nipple adenoma: a review of literature . Ann Breast Surg. 2019, 3:29. 10.21037/abs.2019.10.03

3. Spohn GP, Trotter SC, Tozbikian G, Povoski SP: Nipple adenoma in a female patient presenting with persistent erythema of the right nipple skin: case report, review of the literature, clinical implications, and relevancy to health care providers who evaluate and treat patients with dermatologic conditions of the breast skin. BMC Dermatol. 2016, 16:4. 10.1186/s12895-016-0041-6

4. Rosen PP, Caicco JA: Florid papillomatosis of the nipple. A study of 51 patients, including nine with mammary carcinoma. Am J Surg Pathol . 1986, 10:87-101.

5. Jones MW, Tavassoli FA: Coexistence of nipple duct adenoma and breast carcinoma: a clinicopathologic study of five cases and review of the literature. Mod Pathol. 1995, 8:633-636.

6. Da Costa D, Taddese A, Cure ML, Gerson D, Poppiti R Jr, Esserman LE: Common and unusual diseases of the nipple-areolar complex. Radiographics. 2007, 27:S65-S77. 10.1148/rg.27si075512

7. Koerner FC: Papilloma and related benign lesions. Rosen's Breast Pathology, 4th Edition. Hoda SA, Brogi E, Koerner FC, Rosen PP (ed): Lippincott Williams \& Wilkins, Philadelphia, PA; 2014. 95-152.

8. DI Bonito M, Cantile M, Collina F, et al.: Adenoma of the nipple: a clinicopathological report of 13 cases . Oncol Lett. 2014 , 7:1839-1842. 10.3892/ol.2014.2000

9. Sasi W, Banerjee D, Mokbel K, Sharma AK: Bilateral florid papillomatosis of the nipple: an unusual indicator for metachronous breast cancer development-a case report. Case Rep Oncol Med. 2014, 2014:432609. $10.1155 / 2014 / 432609$

10. Lee C, Boughey J: Case report of a synchronous nipple adenoma and breast carcinoma with current multimodality radiologic imaging. Breast J. 2016, 22:105-110. 10.1111/tbj.12531

11. Zhao H, Han Y, Zhang D, et al.: Sonographic, microscopic, and immunohistochemical features of nipple adenoma coexisting with intra-ductal papillary carcinoma: a rare case report. Int J Clin Exp Med. 2019, $12: 2851-2856$.

12. Aftab K, Idrees R, Rauf F, Kayani N: Nipple adenoma of breast: a masquerader of malignancy . J Coll Physicians Surg Pak. 2010, 20:472-474.

13. Liau JY, Lee YH, Tsai JH, et al.: Frequent PIK3CA activating mutations in nipple adenomas . Histopathology. 2017, 70:195-202. 10.1111/his.13043

14. Sanders MA, Brock JE, Harrison BT, et al.: Nipple-invasive primary carcinomas: clinical, imaging, and pathologic features of breast carcinomas originating in the nipple. Arch Pathol Lab Med. 2018, 142:598-605 10.5858/arpa.2017-0226-OA 